\title{
Introduction to the Special Issue on Expanding Worldviews: Astrobiology, Big History, and the Social and Intellectual Benefits of the Cosmic Perspective
}

Ian A. Crawford

Department of Earth and Planetary Sciences Birkbeck College, University of London, UK

Correspondence | Ian A. Crawford, i.crawford@bbk.ac.uk Citation | Crawford, I. A. (2019) Introduction to the Special Issue on: Expanding Worldviews: Astrobiology, Big History, and the Social and Intellectual Benefits of the Cosmic Perspective. Journal of Big History, III(3); p. 1. DOI | https://doi.org/10.22339/jbh.v3i3.3310

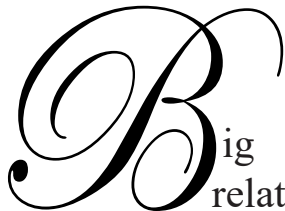

ig history and astrobiology are two relatively new academic disciplines, the former aiming to integrate human history with the wider history of the universe, and the latter searching for life elsewhere in that universe. Despite differences in emphasis, these two disciplines share much in common, especially their interdisciplinarity and the cosmic and evolutionary perspectives that they both engender. To explore these relationships, and to investigate their wider societal implications, a one-day meeting on the theme of 'Expanding Worldviews: Astrobiology, Big History, and the Social and Intellectual Benefits of the Cosmic Perspective' was held on 19 July 2018 under the auspices of the Humanities Research Centre at the Australian National University. ${ }^{1}$

This special issue of the Journal of Big History contains the peer-reviewed versions of seven papers presented at that meeting (i.e. those by Elise Bohan, David Christian, Ian Crawford, Chris Hamer, Charley Lineweaver, Mark Lupisella and John Stewart), together with three additional papers (by Charley Lineweaver \& Aditya Chopra, Fred Spier, and Joseph Voros) that were inspired by the theme of the meeting. The participants at the meeting also contributed to original research through interdisciplinary discussion and intellectual synthesis. This is reflected in the diverse range of content and styles of the published papers. Whereas some of these papers present the results of original research, others are more subjective and offer personal reflections and/or original interpretations of previously published work. Taken together, they provide a broad, if eclectic, overview of the interactions of big history and astrobiology and their wider implications for society.

\section{Acknowledgements}

I thank all the authors for contributing to this special issue of the Journal of Big History. I also thank the Humanities Research Centre at the Australian National University, and especially Professor Will Christie and Ms Penny Brew, for hosting the meeting on which it is based. I would also like to thank the editor of $J B H$, Professor Lowell Gustafson, for offering to host these papers, and the anonymous reviewers who offered very useful suggestions.

1. For a published summary of the meeting, see: Crawford, I.A., "Big History and the Cosmic Perspective," Astronomy and Geophysics 59, 5.33-5.36 (2018). Available on-line at: https:// www.researchgate.net/publication/327766260 Big_History and the Cosmic Perspective 
